Bryant University

Bryant Digital Repository

$1-7-2020$

\title{
Measuring and Unpacking Affective Polarization on Twitter: The Role of Party and Gender in the 2018 Senate Races
}

\author{
Kevin Mentzer \\ Bryant University, kmentzer@bryant.edu \\ Kate Fallon \\ Bryant University, katefallonn@gmail.com \\ Janet Prichard \\ Bryant University, prichard@bryant.edu \\ David Yates \\ Bentley University, dyates@bentley.edu
}

Follow this and additional works at: https://digitalcommons.bryant.edu/cisjou

Part of the Business Analytics Commons, Management Information Systems Commons, and the Other Business Commons

\section{Recommended Citation}

Mentzer, Kevin; Fallon, Kate; Prichard, Janet; and Yates, David, "Measuring and Unpacking Affective Polarization on Twitter: The Role of Party and Gender in the 2018 Senate Races" (2020). Computer Information Systems Journal Articles. Paper 30.

https://digitalcommons.bryant.edu/cisjou/30

This Article is brought to you for free and open access by the Computer Information Systems Faculty Publications and Research at Bryant Digital Repository. It has been accepted for inclusion in Computer Information Systems Journal Articles by an authorized administrator of Bryant Digital Repository. For more information, please contact dcommons@bryant.edu. 


\section{Measuring and Unpacking Affective Polarization on Twitter: The Role of Party and Gender in the 2018 Senate Races}

\author{
Kevin Mentzer \\ Bryant University \\ kmentzer@bryant.edu
}

\author{
Kate Fallon \\ Bryant University \\ katefallonn@gmail.com
}

\author{
Janet Prichard \\ Bryant University \\ prichard@bryant.edu
}

\author{
David J. Yates \\ Bentley University \\ dyates@bentley.edu
}

\begin{abstract}
This study examines how the Twittersphere talked about candidates running for the U.S senate in the 2018 congressional elections. We classify Twitter users as Liberal or Conservative to better understand how the two groups use social media during a major national political election. Using tweet sentiment, we assess how the Twittersphere felt about in-group party versus outgroup party candidates. When we further break these findings down based on the candidates' gender, we find that male senatorial candidates were talked about more positively than female candidates. We also find that Conservatives talked more positively about female Republican candidates than they did about Republican male candidates. Female candidates of the out-group party were talked about the least favorably of all candidates. Conservative tweeters exhibit the most positive level of in-group party sentiment and the most negative level of out-group party sentiment. We therefore attribute the most intense affective polarization to this ideological group.
\end{abstract}

\section{Introduction}

Partisan polarization in the United States Congress is at the core of many challenges that Congress faces in order to become more effective [33]. It increases gridlock, decreases the quality of the legislation that guides the governance of the country, and harms the functioning of the executive and judicial branches of government [37]. Unfortunately, the level of partisan polarization has increased in the 21 st century. In part this has been in reaction to watershed events such as the presidential elections of 2000, 2008 and 2016 [44, 45] and the confirmation of six justices to the Supreme Court by the U.S. Senate [12].

When discussing partisan polarization it is important to distinguish between different types of polarization. For example, ideological polarization is the extent to which the ideological policy positions differ between parties [2] whereas affective polarization is the extent to which supporters of one party (or group) dislike the members of other parties (or other groups) [27]. While most studies, when measuring partisan polarization, have focused on ideological polarization, the focus of this work is to examine affective polarization. It is vital that we understand the drivers of this type of polarization since affective polarization can lead to democratic erosion [19]. As the general public increasingly turns to social media for their source of information [53], and partisan discourse leads to an increase in affective polarization $[38,50]$, it is important to understand the discourse on social media during election campaigns [49].

Even though progress has been made towards decreasing the gender disparity among public officials at many levels of government [17], it is important to measure, track, and understand how this disparity is changing over time [52]. Specifically, it is important to unpack to what extent the projection of gender stereotypes onto congressional candidates is being perpetuated during national elections $[13,16,18,25$, 26].

It is ironic that at a time when the language of polarization has become male stereotyped, e.g., using words like warfare, warriors, and combatants [22, 30, 46], that women voters have the most power to shape the future of partisan polarization as they vote. According to Carroll and Fox [8], women are the largest demographic block of registered voters in the U.S. and about 9.9 million more women voted than men in the 2016 election.

\subsection{Affective Polarization}

The main goals of this study are to a) determine whether affective polarization can be measured using Twitter data and b) to unpack affective polarization, as it is expressed on Twitter [28], to better understand what may be driving this polarization. Iyengar et al. [27], using data from the American National Election Study (ANES), measure affective polarization as the difference between mean in-party feeling and mean outparty feeling. They show that affective polarization has significantly increased over the last three decades. We propose and define a Twitter-based measure of affective 
polarization as the difference between mean in-group party tweet sentiment [48] and mean out-group party sentiment [29]. This Us-versus-Them [19] measure provides a way to quantify the level of mass affective polarization, by measuring the animosity between ideological groups or political parties, in near real-time. We use the U.S. Senate elections in 2018 as the empirical context to test the validity of this measure and use the tweets gathered about (or by) candidates running for Senate to unpack what is behind affective polarization on Twitter. We will unpack the data based upon four different dimensions:

- Ideology and gender of Twitter user; and,

- Party and gender of senatorial candidate(s) mentioned in the tweet.

Through this analysis we will better understand what role gender plays, both the gender of the citizen as well as gender of the candidate, with respect to affective polarization.

The remainder of this paper is organized as follows: The next section is a literature review focused on partisan polarization and differences and disparities in U.S. politics and elections that are driven by party and gender. Section 3 describes our data and methods. Section 4 presents and discusses our results. Section 5 presents our conclusions and we cover limitations and future work in Section 6.

\section{Polarization, Party and Gender}

Mass partisan polarization among citizens is most commonly measured using surveys and focus groups [36] and has focused on ideological polarization [2]. During an election cycle such tools are supplemented with frequent opinion polls [1]. Since roll-call votes, answers to questions, coded interview data, and responses to polls are very often tied to the party and gender of a public official, a candidate, or a respondent, the data produced by these instruments has been of keen interest to many scholars, e.g., $[8,31]$. Of course, such research has sometimes focused on the connections between polarization and party [51], gender [43], or both $[16,26]$. In the age of social media, this work has been extended to determine and characterize differences in public opinion and sentiment on a variety of topics [3, 41, 47, 49]. Within this body of work, Twitter has increasingly played a key role, rapidly speeding up both the scope of political campaigns and their coverage while providing researchers with a rich source of data.

Tweets reflect the thoughts of millions of people in real-time. In 280 characters or less, a candidate, journalist, or voter can publish their thoughts for others to see. While discussions questioning the validity of polls and their predictive power on election outcomes have increasingly circulated since Donald Trump's victory in 2016, Twitter's role has only broadened, transforming it into a catalyst for political communication as well as a gauge for public opinion $[24,53]$.

\subsection{Measuring Twitter-Based Affective Polarization}

Early work in the social media era analyzed online citizen sentiment and emotion with the goal of measuring public opinion [42] and even predicting election results [7]. However, systematic ways of making complex inferences like predicting the results of an election remained, and continue to be, elusive [20].

The present study extends the work of Conover, Dang-Xuan, Iyengar, Steiglitz and others $[10,11,27$, $28,29,48]$ by proposing to systematically measure affective polarization as the difference between sentiment about one's own party (in-group party) [48] and sentiment about opposing parties (out-group parties) [29] as expressed on Twitter.

While we expect affective polarization to be evident, we are cognizant that using social media data comes with some concerns. In particular, the $\mathrm{n}=$ all fallacy [34], which is the assumption that, through the use of "big data," scholars can position their arguments as universal - based on digital trace data - even though these traces might be influenced by social media companies or other organizations [53], and are likely skewed to a younger population than the general public. These limitations thus motivate the exploratory nature of this study.

\subsection{Gender Differences and Disparity}

The existence of gender stereotyping in American politics has been clearly documented, e.g. in [13]. Research in this area has focused on a variety of topics, including the successes and failures of women in elections $[14,15,40]$ and the nature and tone of discourse surrounding women in the public sphere [38].

Even though the link between gender and political representation has evolved, stereotypes can play a role in the actions of voters and women have yet to be seen as equals in the political arena [8].

Differing expectations among voters regarding the capabilities of a politician are routinely based on gender, providing the most consistent evidence to prove the existence of gender stereotyping in politics [43, 54]. In response successful women have recognized where they stand among voters and have crafted their strategy accordingly. The challenge that female candidates must endure within this process is to wage campaigns that showcase any dispositions toward gender as an asset rather than a liability $[4,14,26]$. 
The present climate of partisan polarization and the rapid and efficient transmission of polarizing messages via social media present many challenges to researchers. In general, what means do we have to understand how Liberal and Conservative voters evaluate male and female candidates? We used the following research questions to guide this research:

- RQ1: Can Twitter be used to measure affective polarization?

- RQ2: Does affective polarization differ by ideology or gender of the Twitter user?

- RQ3: Does the party or gender of a candidate affect the level of affective polarization on Twitter?

- RQ4: In the context of congressional elections, does tweet content provide hints as to what issues or events might be fueling affective polarization?

\section{Data and Methods}

This study uses data from a 7-week time frame from September 27 through November 13, 2018. This represents 6 weeks leading up to the election and a week post-election.

There were 33 senate races in the 2018 elections with 102 candidates on the ballots. We identified the primary Twitter handle for 87 candidates; the remainder of the candidates did not have a Twitter account. A Python script using the Twitter Listener API in the Twython library [39] was developed and deployed using the list of handles. Overall we collected 17,178,617 tweets. However, the Twitter API does not just look in the tweet text alone for a match but also looks at URLs, screen names, etc. We filtered the tweets down to those that specifically mentioned at least one candidate in the text of the tweet itself. This reduced our overall tweet dataset down to $12,595,639$.

\subsection{Ideological Affinity}

Accurately predicting political alignment or tendencies has been of significant interest. Many techniques have been employed with varying success. Some of the more popular techniques employed when analyzing Twitter data have been keyword, or hashtag, analysis, analyzing the follower network, and analyzing the retweet network. Conover et al. [10] report a 95\% success rate when utilizing the retweet approach. We should note that others have found this approach not as successful when the conversation being analyzed was non-political [9]. Since our conversation is political in nature, we adopted this approach.

From our database of tweets we identified and extracted the retweets. These were then used to identify how frequently someone retweeted someone else. This data was used to build a weighted and directed social network which we imported into the networking tool Gephi [6]. Only those users who either retweeted someone else, or were retweeted by someone, were imported into Gephi. Users who didn't participate in retweeting were excluded. While our approach forced us to exclude users who did not participate in retweeting, we feel this was justified since the primary motivation for political speech is to spread the message which is accomplished through retweets. The result was $1.4 \mathrm{M}$ unique Twitter users identified as retweet participants with $4.7 \mathrm{M}$ weighted connections between those participants.

Using the Gephi software tool, we used this weighted directed network to identify communities within the network. Gephi found 484,701 communities. While the number of individual communities was quite large, we found that we could account for $63 \%$ of participants by using the top 10 communities, with each participant being assigned to one and only one community. Once we moved beyond the top 10 communities, the subsequent communities represented $0.11 \%$ or less of the total number of nodes.

To assign an ideological affinity to each community we looked at the top 10 retweeted users in each and manually classified these accounts as Liberal or Conservative. These are the users whose message is being spread the most by the community and therefore, we argue, best represent the ideology of that community. For example, the largest community represents $28.59 \%$ of all nodes with the top two retweeted accounts managed by anti-Trump brothers Brian and Ed Krassenstein (these accounts have since been banned by Twitter). This network was classified as Liberal. The second largest network represents $21.71 \%$ of all nodes with the number one retweeted account being@realdonaldtrump (President Trump's personal Twitter account). This network was classified as Conservative.

In all communities with the exception of one discussed below, the top 10 accounts matched in their ideological affinity. In the final case it was unclear which ideology to assign to this community based on the top 10 accounts. In this case the top retweeted accounts were all discussing immigration issues related to professionals coming mainly from Asian countries. The primary accounts did not appear to be promoting one set of candidates over the other. We will discuss why we classified these accounts as Liberal next.

Following the manual classification, we used Gephi to visualize the network using the Force Atlas 2 layout algorithm [32]. As can be seen in Figure 1, two large distinct communities emerged and appear as the dark pink (the primary Liberal community) and green (the primary Conservative community). Barberá et al. [5] 
found a similar clear pattern of two distinct ideologies when displaying the follower network in the 2012 election. Using proximity to these two communities we validate the classification of each sub-community. In all cases, our manual classification was supported by the proximity to primary community. For the immigration community (shown as a small purple community to the left of the Liberal communities) we found that it truly was segmented off to the side, however there were more connections into the other Liberal communities than into the Conservative communities and, as such, we classified this community as Liberal.

Next we exported the community information out of Gephi in order to assign an ideological affinity back to our tweet dataset. Using the community identification, and the membership of each user, we were able to assign the community back to the original tweet dataset, including those that were not involved in retweets. While we only manually classified the top 10 communities which represented $63.09 \%$ of those accounts who were involved with retweeting, those accounts represented $78.9 \%$ of all the tweets gathered during our 7-week period. This represents just under $10 \mathrm{M}$ tweets and is the dataset we used for the rest of our analysis. (See Table 2 in the online Appendix.) Overall, the split of total tweets was $50 \%$ Liberal and $50 \%$ Conservative showing that both ideological groups had the same level of discussion occurring.

\subsection{Sentiment}

Next we scored each tweet for sentiment. We began by stripping all punctuation from the tweet text. Each tweet was scored for sentiment using the Python TextBlob library [35]. Sentiment score ranges from -1 (extremely negative) to +1 (extremely positive). For example, the following retweet was scored -1.0 (extremely negative):

"rt harrietbaldwin amyklobuchar you are going to lose disgusting duplicitous democrat"

and this tweet was scored 1.0 (extremely positive):

"the very best man to serve all connecticut residents without bias [ vote mattcoreyct takebackct"

\subsection{Gender Classification}

To identify the gender of the Twitter user we used the Python based Gender-guesser library [21]. This package predicts a gender based on the first name. We broke out the Twitter username and used the first word in that name as the first name. Each name was classified as either female, male, mostly-female, mostly-male, androgynous or unknown. We grouped these results into male (including male and mostly-male), female (including female and mostly female), and unknown (including androgynous and unknown). While we see

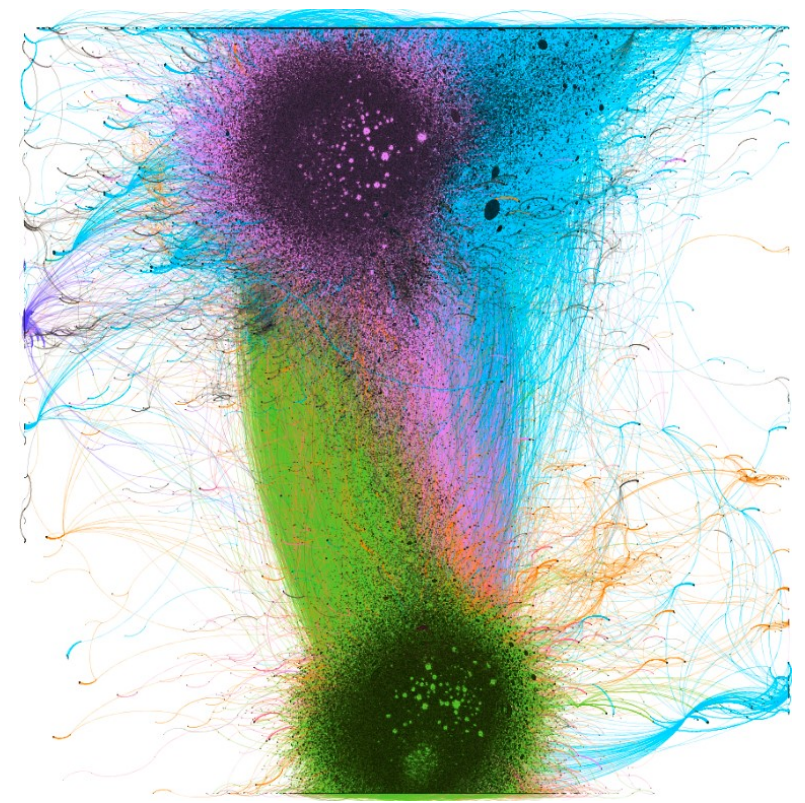

Figure 1. Social network of retweet network

significant differences in sentiment for the male, female, and unknown groups, the mostly-male, mostly-female, and androgynous groups become impossible to distinguish. This is expected considering each of these groups would have varying levels of males and females. As a result, when analyzing gender we used just the pure groups and did not include the "mostly" groups.

\subsection{Other Classifications}

Finally, each tweet was classified as male-only, female-only, or combination, depending on the candidates mentioned in the tweet. A similar approach was then used to classify each tweet as mentioning Democrat-only candidates, Republican-only candidates, Other-party-only candidates, or some combination of parties mentioned.

\section{Results}

The average sentiment score across all tweets mentioning any candidates was .0861, meaning, overall, the tweets were more positive than they were negative. $49 \%$ of the tweets were neutral (sentiment $=0$ ), $35 \%$ positive (sentiment $>0$ ), and $16 \%$ negative (sentiment $<$ $0)$. This distribution of positive/neutral/negative tweets is similar to results found in the 2016 [23].

When broken down by the ideology of the tweeter, tweets from Liberals were more positive (sentiment $=0.0851$ ) than those originating from Conservatives (sentiment $=0.0779, p<.0001$ ). There 
were approximately 5 million tweets for each of the two ideologies indicating that neither ideology dominated the senate discussion in the Twittersphere. Both had $68 \%$ of tweets being retweets and $32 \%$ being original tweets. Retweets tended to be more positive (sentiment $=0.0947)$ than original tweets (sentiment $=0.0535)$.

\subsection{Asymmetry of Affective Polarization}

While we find that Liberals tweet more positively than Conservatives, what happens when either discusses their own in-group party or the out-group party (opposing party)? Figure 2a shows the average sentiment score across all 7 weeks based on the ideology of the tweeter broken down by whether the tweet discusses the in-group party only, the opposing party only, or some combination of parties. The sentiments in this figure show us that Conservatives tweet more positively about their own (in-group) candidates, and more negatively about opposing candidates than Liberals. When candidates from multiple parties are discussed within the same tweet then Conservatives tweet slightly more favorably than Liberals.

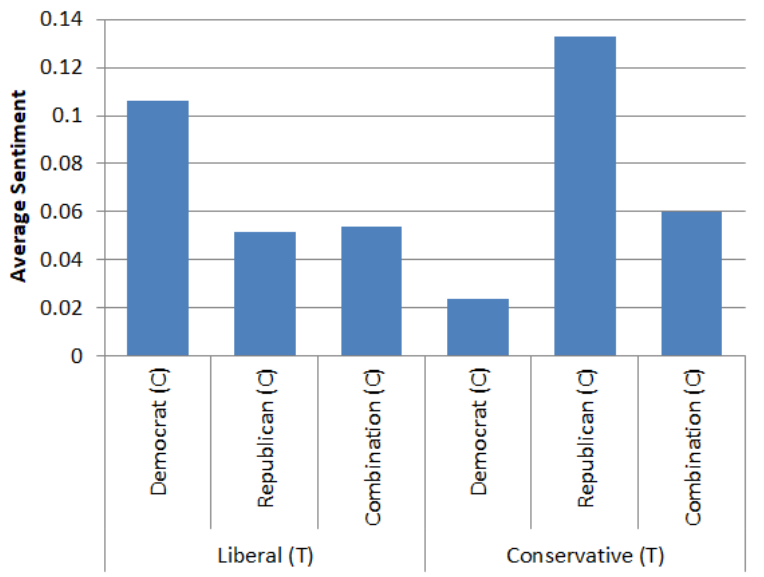

Figure 2a. Sentiment towards candidates by tweeter's ideology

Recall that our measure of affective polarization is the difference between in-group party sentiment and out-group party sentiment. While we can see this difference by comparing the spread of the bars in Figure $2 \mathrm{a}$, Figure $2 \mathrm{~b}$ goes into more detail by showing the range of the overall daily affective polarization across the 7 weeks. The larger median difference (or greater asymmetry) for Conservatives indicates a higher level of affective polarization. The larger range of both the overall bar, and the 50th percentile, for Conservatives indicates that this ideological group also had wider fluctuations in polarization over the 7-week period. This is our first key finding: The level of affective polarization is greater amongst Conservatives than it is amongst Liberals.

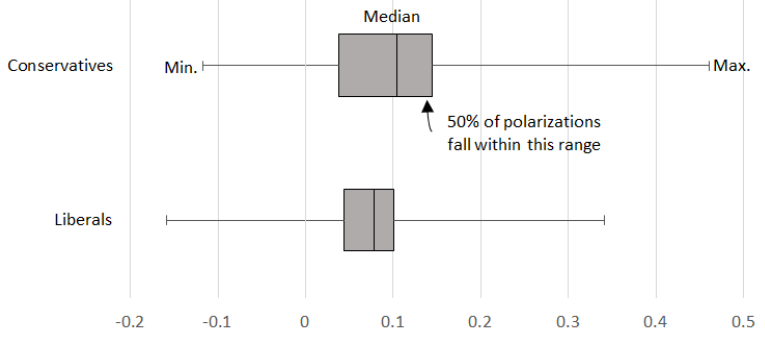

Figure 2b. Asymmetry of Affective Polarization

\subsection{Gender Differences and Polarization}

When considering the gender of the tweeter, several findings come to light. Figure 3 a shows the average sentiment score for the party of the candidate broken down by ideology and gender of the tweeter. For both ideologies, women talk more positively about their ingroup party candidate. A one-way ANOVA between groups show that there was no difference in groups when talking about the out-group (or opposing) party candidate, with the exception of Liberal men who talk more favorably about Republicans than any other group when talking about their opposing party.

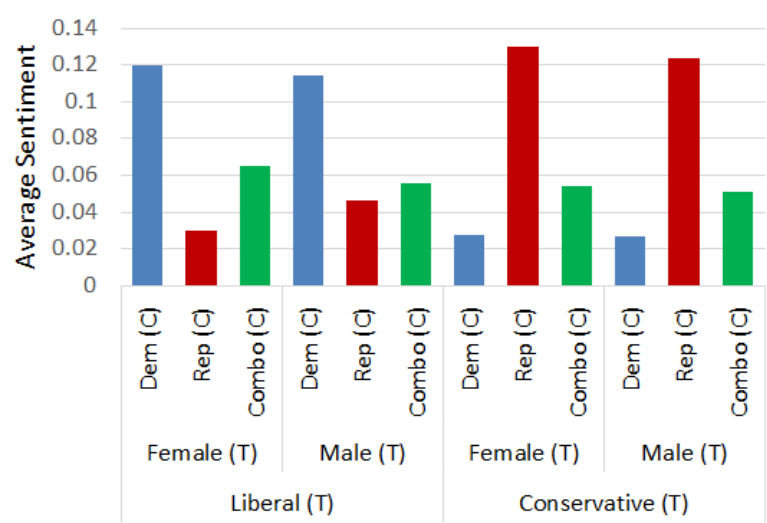

Figure 3a. Sentiment towards candidates by tweeter's gender and ideology

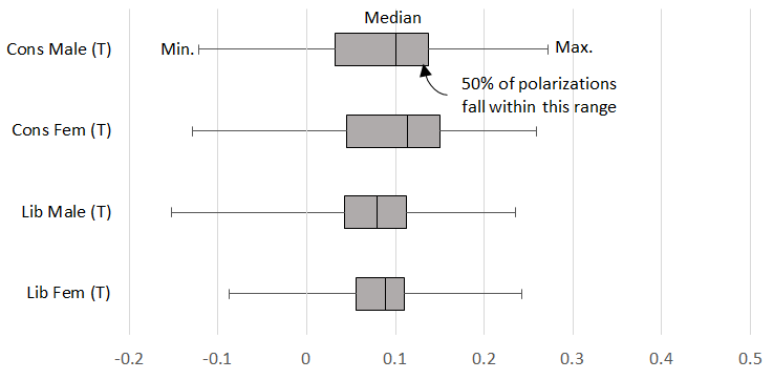

Figure 3b. Average daily polarization by tweeter's gender and ideology

Figure $3 \mathrm{~b}$ shows the range of daily polarization broken out by the gender of the tweeter (see Table 2 and Table 3 in the online Appendix for descriptive 
statistics). We can see that for both ideological groups, women score higher in their level of polarization. Liberals are less polarized than Conservatives, however, we again observe more daily fluctuation among Conservatives.

\subsection{Candidate Gender and Polarization}

In order to understand whether the gender of the candidate has any impact on sentiment, we begin by classifying each tweet as "Female-Only", "Male-Only", or "Both" depending on who was mentioned in each tweet. Figure 4 shows the average sentiment score based on this classification by the gender of the tweeter.

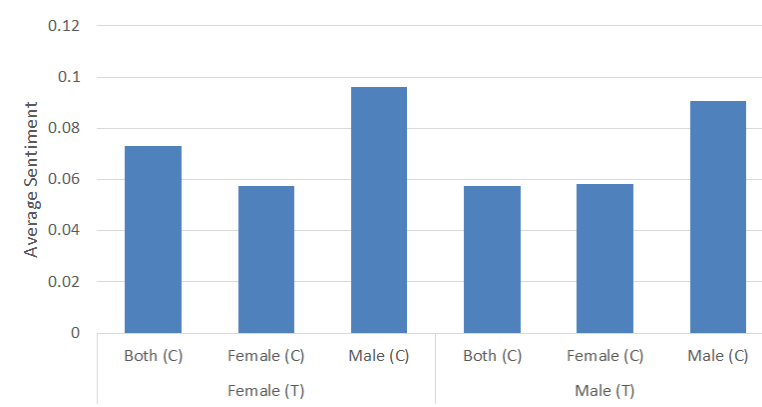

Figure 4. Sentiment towards candidates by their gender and by tweeter's gender

We see that both men and women talk more favorably about male candidates than they do about female candidates. Figure 5 shows the sentiment further broken down by the ideology of the tweeter. Keep in mind that overall women talked more positively about men than they did about women.

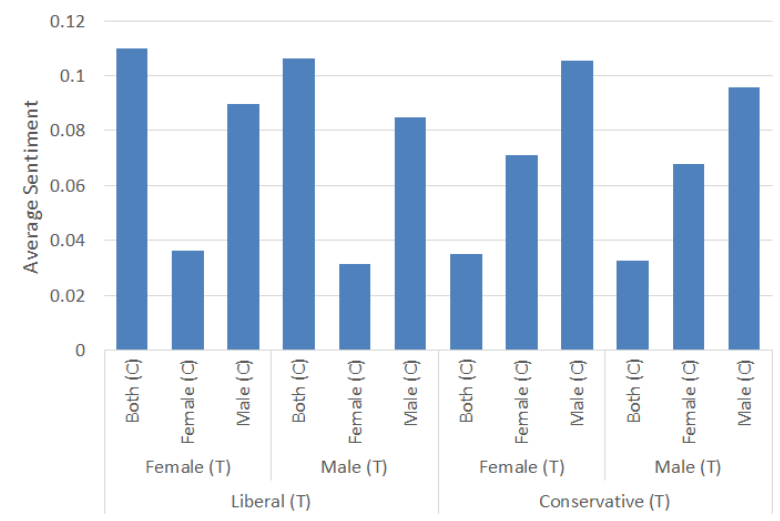

Figure 5. Sentiment towards candidates by their gender and by tweeter's gender and ideology

Figure 5 also shows that party affiliation plays a strong role in this measure. Both Liberals and Conservatives talk more positively about male candidates than female candidates. Liberals talk least favorably about female candidates and have a much wider discrepancy between male and female candidates.
What is surprising about this result is that there were more Democratic female candidates $(n=15)$ than there were Republican female candidates $(n=6)$, and given that people talked more positively about their in-group candidates than the out-group party candidates, it was expected that Liberals would talk more positively about female candidates than Conservatives.

\subsection{Candidate Gender and Party}

To better understand the unexpected findings from Figure 5, we break out sentiment based on all four categories; ideology and gender of the tweeter and gender and party of the candidate. We can see in Figure 6 that candidate party does indeed make a significant difference when evaluating sentiment based on candidate gender.

Regardless of the gender of the tweeter, Liberals talked more positively about male candidates than they did about female candidates. Conservatives talked much more positively about in-group party female candidates than male candidates. Across all groups, female candidates of the out-group party had the lowest overall sentiment score.

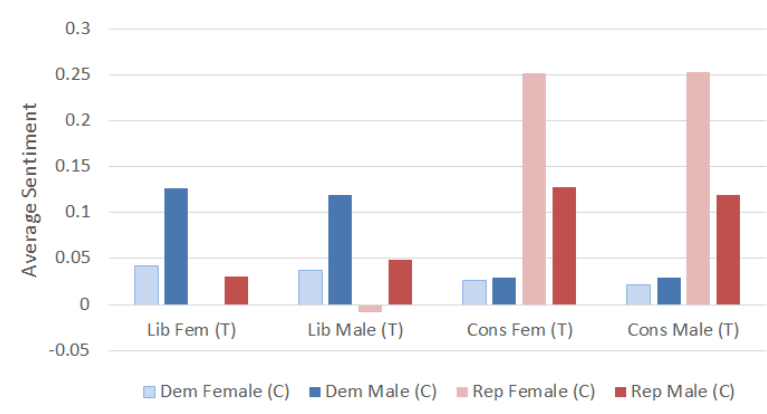

Figure 6. Sentiment towards different candidates by tweeter's ideology and gender

\subsection{Drivers of Affective Polarization}

Given that our measure of polarization is in-group party support versus out-group party support, we can consider that there are certain candidates, issues, and race tenor that will push the in-group party measure higher and the out-group party measure lower, resulting in an increase in affective polarization.

To identify these drivers we segmented the tweets based on the ideology of the tweeter, the party mentioned in the tweet, and whether they are highly positive (sentiment score $>=0.5$ ) or highly negative (sentiment score $<=-0.5$ ). We disregard tweets that did not score highly (either positive or negative) so we can focus in on the drivers of polarization. The result is eight groups of tweets as listed in Table 1.

We then used these groups of tweets to extract the top candidates mentioned, the top hashtags mentioned, 
and the top adjectives used. These categories give us indicators for the drivers of affective polarization based on candidates, issues (as seen through hashtags), and tenor (as seen through adjectives).

We looked at the Liberals in which four of the top five candidates being talked about positively are women and the remaining spot is a man. Two of these candidates (Beto O'Rourke and Dianne Feinstein) are in both the positive and negative groups, suggesting that the polarization pushing up the sentiment score is somewhat offset by a decrease in the sentiment score, so we would not classify either of these candidates as primary drivers of polarization. This leaves the remaining female candidates as the most positivelyrelated polarizing candidates for Liberals (Klobucher, Sinema, and Gillibrand), while Kaine, Warren, and Heitkamp are the Democratic candidates lessening the polarization score since they were talked about the least favorably.

On the other end of affective polarization is the outgroup party score. The lower the average out-group party sentiment, the greater the overall polarization since it increases the Us-vs-Them measure. The primary driver of this would be the highly negative Republican candidates. There is only one candidate (McSally) who appears in the most negative list and whose low score is not offset by also appearing in a number of top positive tweets.

On the Conservative side, four Republican candidates (Cruz, Vukmir, Heller, and Hawley) appear in both lists (positive and negative) somewhat lessening their impact. Patrick Morrisey is the only candidate that is in the top 5 most positively talked about Republican candidates, but is not also in the top 5 most negatively talked about list.

Pushing Conservative affective polarization up is the lower average sentiment score when this group talks about Democrats. We see all 5 candidates (4 of whom are women) appear in both the positive and negative lists. This means that there aren't obvious Democratic candidates who are driving the polarization score for Conservatives.

A key finding from looking at the candidates is that, on the Democratic side, female candidates are clearly eliciting the most reaction, both positively and negatively, across both ideological groups. However, there is not an obvious group of candidates that is driving polarization.

Next we examine the issues to better understand if they are driving the polarization. Using the hashtags as an indicator of issues driving the conversation, we see several mentions of hashtags related to Brett Kavanaugh (Kavanaugh's Senate hearings took place during our period of study), and then singular mentions of topics \#metoo, \#fakenews. Notably absent are topics related to the economy, healthcare, immigration, gun policy, taxes, foreign affairs, etc. In fact, most of the hashtags were focused on specific candidates or races. These findings suggest that in addition to race-specific discourse, affective polarization is being driven discussions surrounding high-profile polarizing public figures, e.g., Brett Kavanaugh and Donald Trump.

Finally we take a look at the top adjectives that appear in the high emotion (positive or negative) tweets. We argue that the tenor of the race can be seen through the adjectives used in tweets. Pride is clearly felt by both ideologies as it appears at the top of both lists. Liberals also feel their candidates are "good" and "great" while Conservatives also use those terms and add in "outstanding" and "fantastic." When discussing the outgroup party negatively. Liberals use terms such as "sad", "pathetic", and "bad" while Conservatives use terms including "bad", "sorry", and "evil."

\section{Conclusions}

In this work we were interested in understanding if affective polarization could be measured using Twitter. To accomplish this, we gathered Twitter data during the 2018 U.S. Senate elections. Using average sentiment scores, we defined a way to measure affective polarization as the difference between sentiment about one's in-group party minus the sentiment about one's out-group party. This measure provides an additional way to look at affective polarization through Twitter, including being able to do so in near real-time, e.g., by measuring polarization using daily averages.

We found a greater level of polarization, and larger fluctuations in polarization, among Conservatives over Liberals. Women having both Liberal and Conservative ideologies expressed stronger in-group party support and greater dislike of out-group party (opposing party) candidates than did their male counterparts.

Both men and women talked more positively about male candidates than they did about female candidates, however, Conservatives were more apt to talk favorably about female candidates than Liberals. The group of candidates uniformly liked least, were female candidates of the opposing party.

We expanded on our findings by using candidate mentions, hashtags, and adjectives for the most strongly worded positive and negative tweets. We find little support that this polarization was being driven by specific candidates or topics, with the exception of the events leading up to Brett Kavanaugh's appointment to the Supreme Court on October 6. Instead we find support that that U.S. Senate races of 2018 were dominated by an Us-vs-Them mentality [19], with Conservatives using the most strongly worded terminology in support of their own (in-group) candidates and against the opposing candidates. 
Table 1. Drivers of polarization

Most Frequently Mentioned:

\begin{tabular}{|c|c|c|c|c|c|}
\hline $\begin{array}{l}\text { Twitter } \\
\text { Users } \\
\end{array}$ & $\begin{array}{l}\text { Talking } \\
\text { about }\end{array}$ & & Candidates & Hashtags & Adjectives \\
\hline \multirow[t]{4}{*}{ Liberals } & $\begin{array}{l}\text { Democratic } \\
\text { Candidates }\end{array}$ & Positively & $\begin{array}{l}\text { Beto O'Rourke (D-TX) } \\
\text { Amy Klobuchar (D-MN) } \\
\text { Kyrsten Sinema (D-AZ) } \\
\text { Kirsten Gillibrand (D-NY) } \\
\text { Dianne Feinstein (D-CA) }\end{array}$ & $\begin{array}{l}\text { \#metoo } \\
\text { \#votewithbeto } \\
\text { \#flipthesenate } \\
\text { \#betodaysarecoming } \\
\text { \#earlyvoting }\end{array}$ & 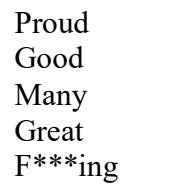 \\
\hline & $\begin{array}{l}\text { Democratic } \\
\text { Candidates }\end{array}$ & Negatively & $\begin{array}{l}\text { Tim Kaine (D-VA) } \\
\text { Beto O'Rourke (D-TX) } \\
\text { Dianne Feinstein (D-CA) } \\
\text { Elizabeth Warren (D-MA) } \\
\text { Heidi Heitkamp (D-ND) }\end{array}$ & $\begin{array}{l}\text { \#trump } \\
\text { \#virginia } \\
\text { \#johnkelly } \\
\text { \#kavanaugh } \\
\text { \#fakenews }\end{array}$ & $\begin{array}{l}\text { Sorry } \\
\text { Impossible } \\
\text { Stupid } \\
\text { Angry } \\
\text { Bad }\end{array}$ \\
\hline & $\begin{array}{l}\text { Republican } \\
\text { Candidates }\end{array}$ & Positively & $\begin{array}{l}\text { Ted Cruz (R-TX) } \\
\text { Rick Scott (R-FL) } \\
\text { Dean Heller (R-NV) } \\
\text { Josh Hawley (R-MO) } \\
\text { Leah Vukmir (R-WI) }\end{array}$ & $\begin{array}{l}\text { \#betofortexas } \\
\text { \#texasdebate } \\
\text { \#nevada } \\
\text { \#kavanaugh } \\
\text { \#votebeto }\end{array}$ & $\begin{array}{l}\text { Good } \\
\text { More } \\
\text { Happy } \\
\text { Great } \\
\text { Sexual }\end{array}$ \\
\hline & $\begin{array}{l}\text { Republican } \\
\text { Candidates }\end{array}$ & Negatively & $\begin{array}{l}\text { Ted Cruz (R-TX) } \\
\text { Leah Vukmir (R-WI) } \\
\text { Dean Heller (R-NV) } \\
\text { Josh Hawley (R-MO) } \\
\text { Martha McSally (R-AZ) }\end{array}$ & $\begin{array}{l}\text { \#betoforsenate } \\
\text { \#betofortexas } \\
\text { \#lyinted } \\
\text { \#trump } \\
\text { \#florida }\end{array}$ & $\begin{array}{l}\text { Sad } \\
\text { Encouraging } \\
\text { Pathetic } \\
\text { Bad } \\
\text { Afraid }\end{array}$ \\
\hline \multirow[t]{4}{*}{ Conservatives } & $\begin{array}{l}\text { Democratic } \\
\text { Candidates }\end{array}$ & Positively & $\begin{array}{l}\text { Dianne Feinstein (D-CA) } \\
\text { Beto O'Rourke (D-TX) } \\
\text { Elizabeth Warren (D-MA) } \\
\text { Kyrsten Sinema (D-AZ) } \\
\text { Kirsten Gillibrand (D-NY) }\end{array}$ & $\begin{array}{l}\text { \#loomered } \\
\text { \#1024something } \\
\text { \#votered } \\
\text { \#confirmkavanaugh } \\
\text { \#scotus }\end{array}$ & $\begin{array}{l}\text { Good } \\
\text { Own } \\
\text { More } \\
\text { Sure } \\
\text { Great }\end{array}$ \\
\hline & $\begin{array}{l}\text { Democratic } \\
\text { Candidates }\end{array}$ & Negatively & $\begin{array}{l}\text { Dianne Feinstein (D-CA) } \\
\text { Beto O'Rourke (D-TX) } \\
\text { Kyrsten Sinema (D-AZ) } \\
\text { Elizabeth Warren (D-MA) } \\
\text { Kirsten Gillibrand (D-NY) }\end{array}$ & $\begin{array}{l}\text { \#azsen } \\
\text { \#electionshaveconsequences } \\
\text { \#suckituptoots } \\
\text { \#betoorourke } \\
\text { \#sundaythoughts }\end{array}$ & $\begin{array}{l}\text { Illegal } \\
\text { Bad } \\
\text { Sorry } \\
\text { Evil } \\
\text { Fake }\end{array}$ \\
\hline & $\begin{array}{l}\text { Republican } \\
\text { Candidates }\end{array}$ & Positively & $\begin{array}{l}\text { Ted Cruz (R-TX) } \\
\text { John James (R-MI) } \\
\text { Patrick Morrisey (R-WV) } \\
\text { Josh Hawley (R-MO) } \\
\text { Matt Rosendale (R-MT) }\end{array}$ & $\begin{array}{l}\text { \#txsen } \\
\text { \#choosecruz } \\
\text { \#cruzcrew } \\
\text { \#keeptexasred } \\
\text { \#michigan }\end{array}$ & $\begin{array}{l}\text { Proud } \\
\text { Great } \\
\text { Good } \\
\text { Outstanding } \\
\text { Fantastic }\end{array}$ \\
\hline & $\begin{array}{l}\text { Republican } \\
\text { Candidates }\end{array}$ & Negatively & $\begin{array}{l}\text { Ted Cruz (R-TX) } \\
\text { Rick Scott (R-FL) } \\
\text { Bob Hugin (R-NJ) } \\
\text { Josh Hawley (R-MO) } \\
\text { John James (R-MI) }\end{array}$ & $\begin{array}{l}\text { \#brendasnipes } \\
\text { \#trump2020 } \\
\text { \#vasen } \\
\text { \#redwave2018andbeyo } \\
\text { \#nd } \\
\text { \#nj }\end{array}$ & $\begin{array}{l}\text { Crazy } \\
\text { Corrupt } \\
\text { Illegal } \\
\text { Sorry } \\
\text { Fake }\end{array}$ \\
\hline
\end{tabular}




\section{Limitations and Future Research}

While we propose a novel measure for affective polarization, without longitudinal data we cannot comment on the change in this measure over time. We have also not tried to quantify the differences in our measures when comparing across groups other than saying they are larger or smaller. We anticipate exploring this in more detail by including additional election datasets.

Our Twitter dataset relies on a gender guessing process which left the majority of tweets classified as from someone with unknown gender. We see some stark differences in how these "unknown" populations scored for sentiment between Liberals and Conservatives (e.g., see Figure 5) which is an opportunity for future exploration. There were also several days during our period of study where one ideology dipped into negative territory for affective polarization; meaning that tweets of that day talking about out-group party candidates were more positive than tweets about their own candidates. These were not gradual changes, but instead were downward spikes when viewed over time. This happened three times for Liberals and once for Conservatives, and could be an indication of either specific events occurring or a concentrated effort to drive the conversation negatively by an external group.

Recall that our sentiment scoring mechanism is limited to words appearing in tweets. Because of this, tweets with only links to other sources or tweets with no text, such as photos, were not included.

Finally, we would caution about reading too much into the strong in-group party support for Republican female candidates. These numbers decrease significantly when the unknowns are included in our analysis. Also, with only six female candidates on the Republican side, it could swing heavily based on the favorability (or lack thereof) of just one or two candidates.

\section{References}

[1] A. I. Abramowitz, The disappearing center: Engaged citizens, polarization, and American democracy, Yale University Press, 2010.

[2] A. I. Abramowitz and S. Webster, "The rise of negative partisanship and the nationalization of US elections in the 21st century", Electoral Studies, 41 (2016), pp. 12-22.

[3] N. Anstead and B. O'Loughlin, "Social media analysis and public opinion: The 2010 UK general election", Journal of Computer-Mediated Communication, 20 (2014), pp. 204220.

[4] M. C. Banwart, "Gender and candidate communication: Effects of stereotypes in the 2008 election", American Behavioral Scientist, 54 (2010), pp. 265-283.
[5] P. Barberá, J. T. Jost, J. Nagler, J. A. Tucker and R. Bonneau, "Tweeting from left to right: Is online political communication more than an echo chamber?", Psychological Science, 26 (2015), pp. 1531-1542.

[6] M. Bastian, S. Heymann and M. Jacomy, Gephi: An open source software for exploring and manipulating networks, Third international AAAI conference on weblogs and social media, 2009.

[7] A. Bermingham and A. Smeaton, On using Twitter to monitor political sentiment and predict election results, Proceedings of the workshop on sentiment analysis where AI meets psychology (SAAIP 2011), 2011, pp. 2-10.

[8] S. J. Carroll and R. L. Fox, Gender and elections: Shaping the future of American politics, Cambridge University Press, 2018.

[9] R. Cohen and D. Ruths, Classifying political orientation on Twitter: It's not easy!, Seventh international AAAI conference on weblogs and social media, 2013.

[10] M. D. Conover, J. Ratkiewicz, M. Francisco, B. Gonçalves, F. Menczer and A. Flammini, Political polarization on Twitter, Fifth international AAAI conference on weblogs and social media, 2011.

[11] L. Dang-Xuan, S. Stieglitz, J. Wladarsch and C. Neuberger, "An investigation of influentials and the role of sentiment in political communication on Twitter during election periods", Information, Communication \& Society, 16 (2013), pp. 795-825.

[12] N. Devins and L. Baum, The company they keep: How partisan divisions came to the Supreme Court, Oxford University Press, 2019.

[13] K. Dolan, "Do women candidates play to gender stereotypes? Do men candidates play to women? Candidate sex and issues priorities on campaign websites", Political Research Quarterly, 58 (2005), pp. 31-44.

[14] K. Dolan, "Gender stereotypes, candidate evaluations, and voting for women candidates: What really matters?", Political Research Quarterly, 67 (2014), pp. 96-107.

[15] K. Dolan, "The impact of gender stereotyped evaluations on support for women candidates", Political Behavior, 32 (2010), pp. 69-88.

[16] K. Dolan and T. Lynch, "Do candidates run as women and men or Democrats and Republicans? The impact of party and sex on issue campaigns", Journal of Women, Politics \& Policy, 38 (2017), pp. 522-546.

[17] K. Dolan and T. Lynch, "The impact of gender stereotypes on voting for women candidates by level and type of office", Politics \& Gender, 12 (2016), pp. 573-595.

[18] H. K. Evans and J. H. Clark, "“You tweet like a girl!" How female candidates campaign on Twitter", American Politics Research, 44 (2016), pp. 326-352.

[19] J. McCoy, T. Rahman and M. Somer, "Polarization and the global crisis of democracy: Common patterns, dynamics, and pernicious consequences for democratic polities", American Behavioral Scientist, 62 (2018), pp. 16-42.

[20] D. Gayo-Avello, "'I wanted to predict elections with Twitter and all I got was this lousy paper"--A balanced survey on election prediction using Twitter data", arXiv preprint arXiv:1204.6441 (2012).

[21] Gender-Guesser, https://pypi.org/project/genderguesser/. 
[22] B. T. Gervais, "Rousing the partisan combatant: Elite incivility, anger, and antideliberative attitudes", Political Psychology 40 (2019), pp. 637-655.

[23] Y. Gorodnichenko, T. Pham and O. Talavera, Social media, sentiment and public opinions: Evidence from \#Brexit and \#USElection, National Bureau of Economic Research (2018).

[24] P. Grover, A. K. Kar, Y. K. Dwivedi and M. Janssen, "Polarization and acculturation in US Election 2016 outcomes-Can Twitter analytics predict changes in voting preferences", Technological Forecasting and Social Change, 145 (2019), pp. 438-460.

[25] D. Hayes, "When gender and party collide: Stereotyping in candidate trait attribution", Politics \& Gender, 7 (2011), pp. 133-165.

[26] D. Hayes and J. L. Lawless, "A non-gendered lens? Media, voters, and female candidates in contemporary congressional elections", Perspectives on Politics, 13 (2015), pp. 95-118.

[27] S. Iyengar, Y. Lelkes, M. Levendusky, N. Malhotra and S. J. Westwood, "The origins and consequences of affective polarization in the United States", Annual Review of Political Science, 22 (2019), pp. 129-146.

[28] S. Iyengar, G. Sood and Y. Lelkes, "Affect, not ideology: A social identity perspective on polarization", Public Opinion Quarterly, 76 (2012), pp. 405-431.

[29] S. Iyengar and S. J. Westwood, "Fear and loathing across party lines: New evidence on group polarization", American Journal of Political Science, 59 (2015), pp. 690707.

[30] G. C. Jacobson, "Partisan polarization in American politics: A background paper", Presidential Studies Quarterly, 43 (2013), pp. 688-708.

[31] G. C. Jacobson and J. L. Carson, The politics of congressional elections, Rowman \& Littlefield, 2016.

[32] M. Jacomy, T. Venturini, S. Heymann and M. Bastian, "ForceAtlas2, a continuous graph layout algorithm for handy network visualization designed for the Gephi software", PloS ONE, 9 (2014), e98679.

[33] D. R. Jones, "Party polarization and legislative gridlock", Political Research Quarterly, 54 (2001), pp. 125 141.

[34] A. Jungherr, "Normalizing digital trace data", Digital discussions: How big data informs political communication (2017).

[35] S. Loria, P. Keen, M. Honnibal, R. Yankovsky, D. Karesh and E. Dempsey, "TextBlob: Simplified text processing", (2014).

[36] S. Mainwaring and M. Torcal, "Party system institutionalization and party system theory after the third wave of democratization", Handbook of Party Politics, 11 (2006), pp. 204-227.

[37] J. Mansbridge and C. J. Martin, "Negotiating agreement in politics", Washington, D.C.: American Political Science Association (2013).
[38] L. Mason, Uncivil agreement: How politics became our identity, University of Chicago Press, 2018.

[39] R. McGrath, "Twython", (2018).

[40] S. C. McGregor and R. R. Mourão, "Talking politics on Twitter: Gender, elections, and social networks", Social Media + Society, 2 (2016), pp. 1-14.

[41] D. Murthy, "Twitter and elections: Are tweets, predictive, reactive, or a form of buzz?", Information, Communication \& Society, 18 (2015), pp. 816-831.

[42] B. O'Connor, R. Balasubramanyan, B. R. Routledge and N. A. Smith, From tweets to polls: Linking text sentiment to public opinion time series, Fourth international AAAI conference on weblogs and social media, 2010.

[43] B. Palmer and D. Simon, Breaking the political glass ceiling: Women and congressional elections, Routledge, 2010.

[44] D. J. Scala and K. M. Johnson, "Political polarization along the rural-urban continuum? The geography of the presidential vote, 2000-2016", The ANNALS of the American Academy of Political and Social Science, 672 (2017), pp. 162-184.

[45] B. F. Schaffner, M. MacWilliams and T. Nteta, "Understanding white polarization in the 2016 vote for president: The sobering role of racism and sexism", Political Science Quarterly, 133 (2018), pp. 9-34.

[46] B. Sinclair, Party wars: Polarization and the politics of national policy making, University of Oklahoma Press, 2014.

[47] N. Spierings and K. Jacobs, "Getting personal? The impact of social media on preferential voting", Political Behavior, 36 (2014), pp. 215-234.

[48] S. Stieglitz and L. Dang-Xuan, "Emotions and information diffusion in social media-Sentiment of microblogs and sharing behavior", Journal of Management Information Systems, 29 (2013), pp. 217-248.

[49] S. Stieglitz and L. Dang-Xuan, "Social media and political communication: A social media analytics framework", Social Network Analysis and Mining, 3 (2013), pp. 1277-1291.

[50] E. Suhay, E. Bello-Pardo and B. Maurer, "The polarizing effects of online partisan criticism: Evidence from two experiments", The International Journal of Press/Politics, 23 (2018), pp. 95-115.

[51] S. M. Theriault, Party polarization in congress, Cambridge University Press, 2008.

[52] D. Thomsen, "Which women win? Partisan changes in victory patterns in US House Elections", Politics, Groups, and Identities (2019), pp. 1-17.

[53] J. A. Tucker, A. Guess, P. Barberá, C. Vaccari, A. Siegel, S. Sanovich, D. Stukal and B. Nyhan, "Social media, political polarization, and political disinformation: A review of the scientific literature", Social Science Research Network Report (2018), March 19.

[54] L. D. Whitaker, Voting the gender gap, University of Illinois Press, 2008. 